Check for updates

Cite this: RSC Adv., 2018, 8, 31564

Received 9th August 2018

Accepted 25th August 2018

DOI: $10.1039 / c 8 r a 06706 f$

rsc.li/rsc-advances

\title{
3D printing of multicolor luminescent glass $\uparrow$
}

\author{
Chang Liu, ${ }^{a}$ Bin Qian, ${ }^{b}$ Rongping Ni, (D) ${ }^{b}$ Xiaofeng Liu*a and Jianrong Qiu (D) *b
}

The development of the stereolithography technique for the additive manufacturing of silica glass has brought revolutionary change in glass manufacturing. Here, we demonstrate the fabrication of 3D luminescent transparent glass parts manufactured by the stereolithographic technique together with solution impregnation and high temperature sintering. Prefabricated glass parts with nanopores were prepared by the stereolithography technique and debinded and pre-sintered at first. To functionalize the additive manufactured glass with photoluminescence, $\mathrm{Eu}^{3+}, \mathrm{Tb}^{3+}$ and $\mathrm{Ce}^{3+}$ ions were doped with a solution impregnation method and further sintered at high temperature. The photoluminescence from these rare earth ions in the blue, cyan and red spectral region can be facilely generated by illumination with a $254 \mathrm{~nm}$ UV lamp. Furthermore, we developed a space-selective doping method that enables the doping of different ions in different parts of a silica glass in a space-selective fashion, resulting in a multicolor luminescent glass object giving distinguishable luminescence from each part.

\section{Introduction}

Glass is an important material used in laboratory, industry and our daily life for its transparency and superior chemical and thermal resistance, which make glass irreplaceable by other materials. However, glass is hard and brittle which makes it extremely difficult for shaping using traditional processing technologies, and this limits the applications of this material. ${ }^{1-4}$ Until now, a number of additive manufacturing (which is also designated as 3D printing) technologies for glass have been developed which brought more flexibility in shaping this material. ${ }^{5-11}$ Among these techniques, stereolithography is the most reliable one due to its higher resolution and lower risk of damage, ${ }^{6,11}$ and this has potential applications for microfluidics, optical lenses and delicate artifacts. ${ }^{12,13}$

The shape is not the only requirement for glass devices; sometimes, optical properties, mechanical properties and bioactivities are required for particular applications. Photoluminescence (PL) is one of the most important properties of glass which is normally introduced through the doping of luminescent ions. Photoluminescent glasses have important applications in white light emission, laser generation and optical temperature sensing. ${ }^{14-16}$ To dope ions in the process of glass additive manufacturing with stereolithography, the method by impregnating the porous glass with solutions

${ }^{a}$ School of Materials Science and Engineering, Zhejiang University, Hangzhou, Zhejiang, China

${ }^{b}$ State Key Laboratory of Modern Optical Instrumentation, School of Optical Science and Engineering, Zhejiang University, Hangzhou, Zhejiang, China. E-mail: qjr@zju. edu.cn

$\dagger$ Electronic supplementary information (ESI) available. See DOI: 10.1039/c8ra06706f containing the target ions followed by sintering is quite suitable as porous glass is the intermediate product in glass additive manufacturing with stereolithography. ${ }^{17-20}$

In this work, $\mathrm{Eu}^{3+}, \mathrm{Ce}^{3+}$ and $\mathrm{Tb}^{3+}$ doped silica glass objects were manufactured with a top-down stereolithographic technique combined with a doping process by solution impregnation. The formation of the dense silica glass was confirmed by scanning electron microscopic (SEM) images, X-ray diffraction (XRD) and Raman spectra. The doped glass showed the characteristic emission of $\mathrm{Eu}^{3+}, \mathrm{Ce}^{3+}$ and $\mathrm{Tb}^{3+}$ ions under the excitation at $254 \mathrm{~nm}$ which was confirmed by the PL spectra. Furthermore, we developed a space-selective doping method which dopes different ions in different parts of a glass device. This technique will have significant implications for glass manufacturing that not only the shape but also the function of a single glass device can be designed, which has great potential for applications in integrated optics.

\section{Experimental}

2-Hydroxyethyl methacrylate (HEMA, 99\%), poly(ethylene glycol) diacrylate 200 (PEGDA 200), diethyl phthalate (99.5\%), 4-methoxyphenol (MEHQ, 99\%), 2,2-dimethoxy-2-phenylacetophenone (DMPA, 99\%), $\mathrm{Eu}\left(\mathrm{NO}_{3}\right)_{3} \cdot 6 \mathrm{H}_{2} \mathrm{O}(99.9 \%), \mathrm{Ce}\left(\mathrm{NO}_{3}\right)_{3} \cdot 6 \mathrm{H}_{2} \mathrm{O}(99.9 \%)$ and $\mathrm{Tb}\left(\mathrm{NO}_{3}\right)_{3} \cdot 5 \mathrm{H}_{2} \mathrm{O}(99.9 \%)$ were provided by Aladdin, China. Amorphous silica nanoparticles (Aerosil OX50) were provided by Evonik, Germany. Tinuvin 1130 was provided by Basf, Germany. Ethanol (99.7\%) was provided by Sinoreagent, China.

$28.1 \mathrm{wt} \%$ HEMA (the reactive monomer), $14.5 \mathrm{wt} \%$ diethyl phthalate (the plasticizer) and 3.7 wt $\%$ PEGDA 200 (the crosslink agent) were mixed to form a homogeneous solution. 53.7 wt $\%$ amorphous silica nanoparticles were added to the solution in 50 doses, and were dispersed with a dissolver (D500, 
Dragonlab) after each dosing. Afterwards, 0.4 wt\% DMPA (the photo initiator) and $0.2 \mathrm{wt} \%$ Tinuvin 1130 (the photo absorber) were dispersed into the mixture.

The additive manufacturing process with a top-down stereolithography system was reported in our previous work. ${ }^{11}$ The hatch distance was set to $70 \mu \mathrm{m}$, the laser power was set to 145 $\mathrm{mW}$ and the scan speed was set to $60 \mathrm{~mm} \mathrm{~s}^{-1}$. The additive manufactured silica-polymer composites (Fig. 1a) were debinded and pre-sintered at $1000{ }^{\circ} \mathrm{C}$ (with the temperature curve shown in Fig. S1a $\dagger$ ) in a muffle furnace (KSL-1100X, Kejing Materials Technology, China). The obtained porous glass objects (Fig. 1b) were immersed in $0.005 \mathrm{~mol} \mathrm{~L}{ }^{-1} \mathrm{Eu}\left(\mathrm{NO}_{3}\right)_{3}$, $\mathrm{Ce}\left(\mathrm{NO}_{3}\right)_{3}$, or $\mathrm{Tb}\left(\mathrm{NO}_{3}\right)_{3}$ ethanol solutions (Fig. 1c) and were kept in these solutions for 15 minutes. These objects were dried at $60{ }^{\circ} \mathrm{C}$ in an electric oven with constant air flow for 1 hour (BPG9040A, Yiheng, China), and then they were moved to a tube furnace (GSL-1400X, Kejing Materials Technology, China) with a corundum tube and were sintered at $1250^{\circ} \mathrm{C}$ for 3 hours (with the temperature curve shown in Fig. $\mathrm{S} 1 \mathrm{~b} \dagger$ ) in vacuum. Silica glass objects (Fig. 1d) with the same shapes were obtained, and the linear shrinkages were around $27.0 \%$. For space-selective doping, droppers were used to drip different solutions on different parts of a porous glass object. The solutions were driven to the body from the surface by capillary forces. Afterwards, the object was dried and sintered in the same way as the normally doped glass.

The emission spectra of the doped silica glass under the excitation at $254 \mathrm{~nm}$ were measured with a fluorescent spectrometer (FLSP920, Edinburgh Instruments, Britain). The photoluminescent photos were shot under the illumination of a $254 \mathrm{~nm}$ UV lamp in a dark room with a smart phone, and the exposure time was set to $1 / 15$ s. Pore distribution and porosity

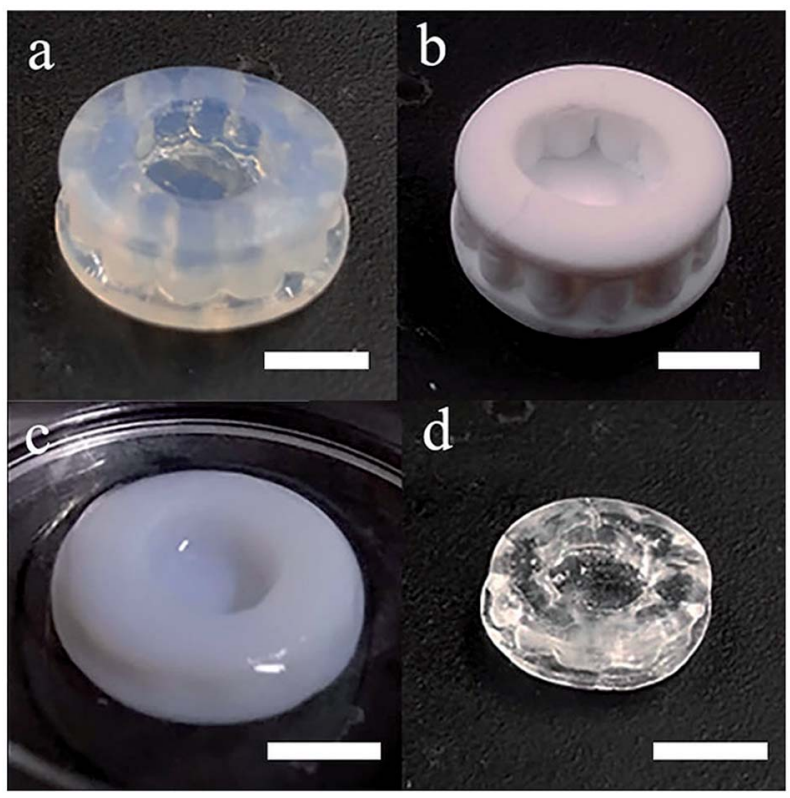

Fig. 1 Photos of (a) the photopolymerized silica-polymer composite, (b) the porous silica glass after debinding, (c) the porous silica glass immersed in ethanol solution of RE ions. (d) The dense silica glass with RE ions doping after sintering. The scale bars represent $5 \mathrm{~mm}$. of the porous silica glass were measured with a nitrogen adsorption instrument (ASAP 2020 HD88, Micromeritics, US). Xray diffraction patterns of the powdered doped silica glass samples were measured with an X-ray diffraction spectrometer (D/MAX 2550/PC, Rigaku). Raman spectra of the doped silica glass were measured with a Raman spectrometer (LabRam HR UV, Jobin-yvon, France) with a $514 \mathrm{~nm}$ laser. The SEM images were taken with a scan electron microscope (Ultra 55, Carl Zeiss Jena, Germany), and a layer of gold was sputtered to the surface of the sample to enhance the conductivity.

\section{Results and discussions}

According to the nitrogen adsorption and desorption experiment (Fig. 2), most of the pores have the width between $30 \mathrm{~nm}$ and $50 \mathrm{~nm}$ and the average value is $31.5 \mathrm{~nm}$. The pores provide enough capillary force that drive the solution to fill these pores. With the porosity, which is $0.316 \mathrm{~cm}^{3} \mathrm{~g}^{-1}$ (41.0 vol\%), the concentration of the RE dopant can be estimated with the formula,

$$
c_{\mathrm{g}}=c_{\mathrm{s}} P \rho_{\mathrm{g}}
$$

where $c_{\mathrm{s}}$ is the RE concentration of the solution, $P$ is the porosity and $\rho_{\mathrm{g}}$ is the density of the silica glass which is $2.20 \mathrm{~g} \mathrm{~cm}^{-3}$. The concentration of $\mathrm{RE}$ ions in the doped glass is found to be 3.48 $\times 10^{-3} \mathrm{mmol} \mathrm{cm}{ }^{-3}$.

The SEM images show the transformation in the microstructure from the silica-polymer composite to the sintered silica glass (Fig. 3). Polymers were totally removed during debinding and the porous glass sample looks like an accumulation of silica powders which contains high volume fraction of pores (Fig. 3b). After sintering, the pores disappear and a smooth surface of the sintered glass is observed (Fig. 3c). The disappearance of the pores during sintering results in the formation of dense, transparent silica glass.

From the XRD pattern shown in Fig. 4a, the broadened hump centered at around $23^{\circ}$ is typical for silica glass and no

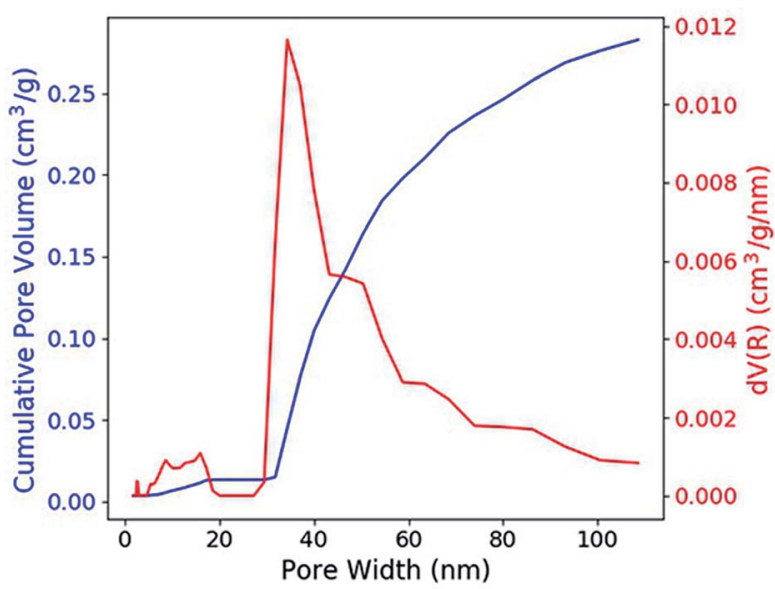

Fig. 2 Cumulative pore volume and the pore width distribution of the porous silica glass. 


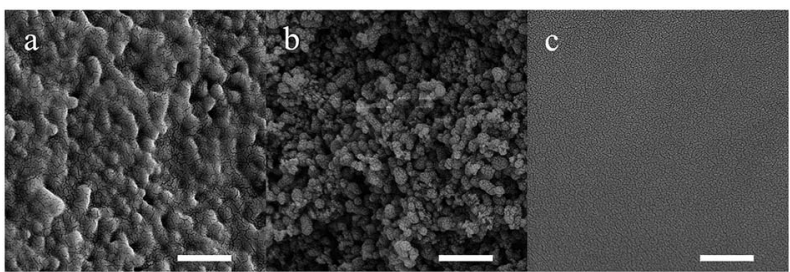

Fig. 3 SEM images of the (a) silica-polymer composite, (b) porous silica glass and (c) sintered silica glass. The scale bars represent $500 \mathrm{~nm}$.

quartz crystals are formed during sintering after doping with RE ions. The Raman spectra of the doped silica glass are similar to that of the fused silica glass (Fig. 4b). The peaks for the breathing mode from 4 and 3 membered ring structures in the silica network around $490 \mathrm{~cm}^{-1}$ and $605 \mathrm{~cm}^{-1}$ are observed, which confirm the formation of silica glass after sintering. ${ }^{21-23}$ The rising Raman scattering intensity of the $\mathrm{Tb}^{3+}$ doped glass from $700 \mathrm{~cm}^{-1}$ to $1200 \mathrm{~cm}^{-1}$ comes from the photoluminescence background from $\mathrm{Tb}^{3+}$ ions excited by the $514 \mathrm{~nm}$ laser.

In Fig. 5, the RE doped glass objects look the same under natural light, because $\mathrm{Eu}^{3+}, \mathrm{Tb}^{3+}$ and $\mathrm{Ce}^{3+}$ ions don't have intense absorption in the visible range due to their low concentration. However, emissions of the $\mathrm{Eu}^{3+}, \mathrm{Tb}^{3+}$ and $\mathrm{Ce}^{3+}$ ions doped glass can be clearly observed under the excitation of
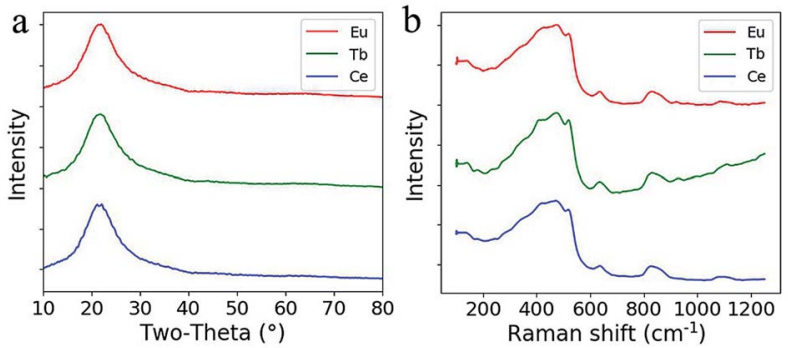

Fig. 4 (a) XRD patterns of the doped silica glass. (b) Raman spectra of the doped silica glass.

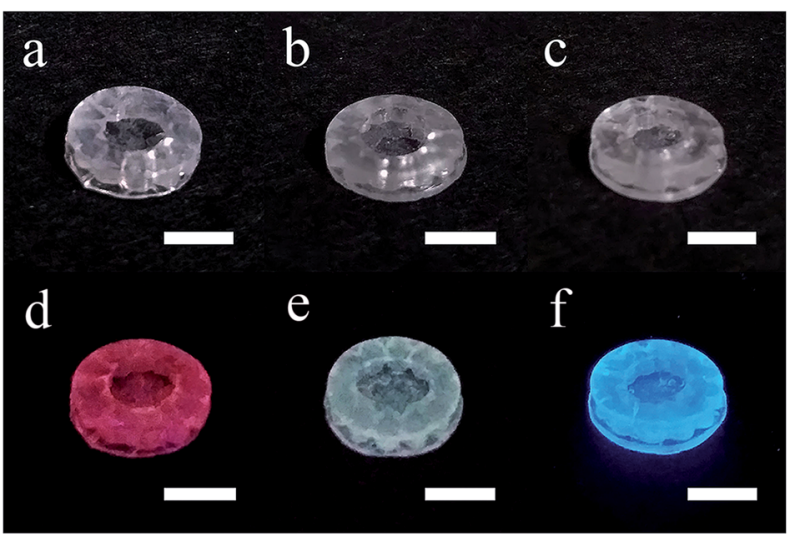

Fig. 5 Photos of the additive manufactured silica glass doped with (a) $\mathrm{Eu}^{3+}$, (b) $\mathrm{Tb}^{3+}$ and (c) $\mathrm{Ce}^{3+}$ ions and (d-f) their luminescent performance under a $254 \mathrm{~nm}$ UV lamp. The scale bars represent $5 \mathrm{~mm}$.
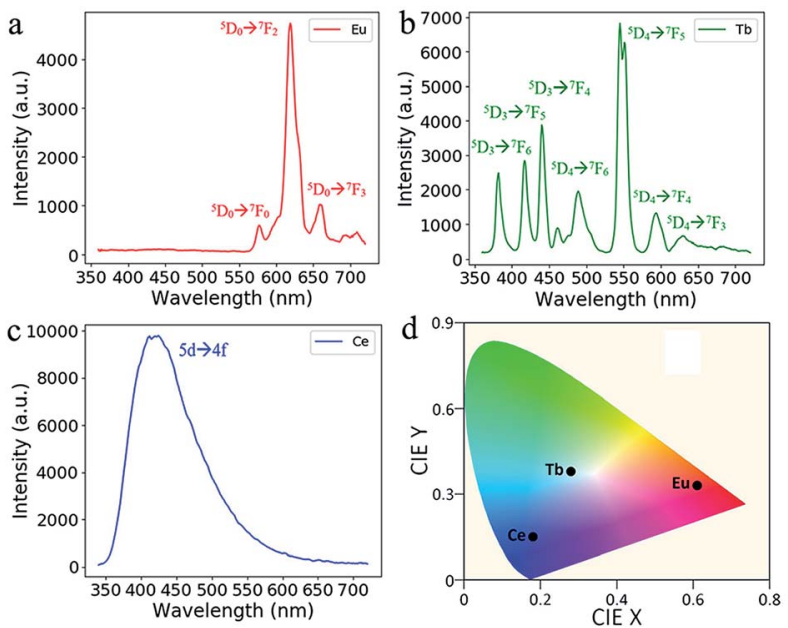

Fig. 6 Emission spectra of the additive manufactured glass doped with (a) $\mathrm{Eu}^{3+}$, (b) $\mathrm{Tb}^{3+}$ and (c) $\mathrm{Ce}^{3+}$ ions under the excitation at $254 \mathrm{~nm}$. (d) The CIE coordinate of the RE-doped glasses.

a $254 \mathrm{~nm}$ lamp. According to the photoluminescence spectra (Fig. 6), the emission peak from the ${ }^{5} \mathrm{D}_{0} \rightarrow{ }^{7} \mathrm{~F}_{2}$ transition of $\mathrm{Eu}^{3+}$ ions at $617 \mathrm{~nm}$ dominates the photoluminescence spectra of the $\mathrm{Eu}^{3+}$ doped silica glass. ${ }^{24}$ The emission peak of the $\mathrm{Ce}^{3+}$ doped silica glass at $350-550 \mathrm{~nm}$ is from the $5 \mathrm{~d} \rightarrow 4 \mathrm{f}$ transitions of $\mathrm{Ce}^{3+}$ ions. ${ }^{25}$ The emission spectra of $\mathrm{Tb}^{3+}$ doped silica glass is much complicated which consists of multiple peaks that distribute from $360 \mathrm{~nm}$ to $650 \mathrm{~nm}$. The emission peak at $550 \mathrm{~nm}$ from the ${ }^{5} \mathrm{D}_{4} \rightarrow{ }^{7} \mathrm{~F}_{5}$ transition of $\mathrm{Tb}^{3+}$ ions shows the highest intensity among all the peaks. ${ }^{26}$

The space-selectively doped glass looks the same as undoped ones under natural light, as the concentrations of the dopants are relatively low. However, under the illumination by a $254 \mathrm{~nm}$ UV lamp, the parts that doped with different ions emitted different lights which are distinguishable by eyes (Fig. 7).

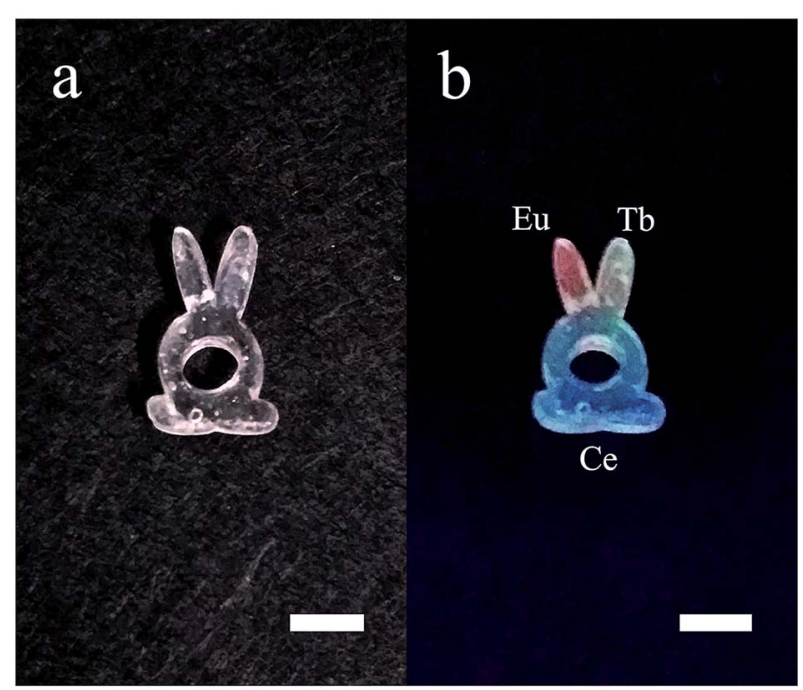

Fig. 7 Photos of the additive manufactured glass with each RE ions doped in different parts. (a) Under natural light and (b) under illumination by a $254 \mathrm{~nm}$ UV lamp. The scale bars represent $5 \mathrm{~mm}$. 
Furthermore, other rare earth ions can be doped and the spatial resolution for doping can be improved. This space-selective doping technique may have important implications in the manufacturing of photonic glasses in the future.

\section{Conclusion}

Luminescent transparent silica glass doped with RE ions were made by additive manufacturing based on stereolithography and solution impregnation. The presence of RE ions does not impede the formation of silica glass, and all the doped objects could be activated by a $254 \mathrm{~nm}$ UV lamp. The $\mathrm{Eu}^{3+}, \mathrm{Tb}^{3+}$ and $\mathrm{Ce}^{3+}$ doped glass objects emitted red, cyan, and blue light under the excitation of the $254 \mathrm{~nm}$ lamp according to the photoluminescent spectra and the CIE coordinate. Furthermore, we developed a space-selective doping method. Different parts of the space-selectively doped glass emitted different light according to the doping ions. This method may enable the design of both the shape and the function in a single glass device.

\section{Conflicts of interest}

There are no conflicts to declare.

\section{Acknowledgements}

This work was financially supported by the National Key R\&D Program of China (Grant No. 2018YFB1107200), the National Natural Science Foundation of China (Grant No. 51472091, 51772270), open funds of State Key Laboratory of Precision Spectroscopy, East China Normal University and State Key Laboratory of High Field Laser Physics, Shanghai Institute of Optics and Fine Mechanics, Chinese Academy of Science.

\section{Notes and references}

1 F. Kotz, N. Schneider, A. Striegel, A. Wolfschlager, N. Keller, M. Worgull, W. Bauer, D. Schild, M. Milich, C. Greiner, D. Helmer and B. E. Rapp, Adv. Mater., 2018, 30, 1707100.

2 A. J. Ikushima, T. Fujiwara and K. Saito, J. Appl. Phys., 2000, 88, 1201-1213.

3 L. L. Hench, D. E. Day, W. Holand and V. M. Rheinberger, Int. J. Appl. Glass Sci., 2010, 1, 104-117.

4 A. Zocca, P. Colombo, C. M. Gomes and J. Gunster, J. Am. Ceram. Soc., 2015, 98, 1983-2001.

5 I. Cooperstein, E. Shukrun, O. Press, A. Kamyshny and S. Magdassi, ACS Appl. Mater. Interfaces, 2018, 10, 1887918885.
6 F. Kotz, K. Arnold, W. Bauer, D. Schild, N. Keller, K. Sachsenheimer, T. M. Nargang, C. Richter, D. Helmer and B. E. Rapp, Nature, 2017, 544, 337-339.

7 J. J. Luo, L. J. Gilbert, C. Qu, R. G. Landers, D. A. Bristow and E. C. Kinzel, Journal of Manufacturing Science and Engineering, 2017, 139, 061006.

8 J. J. Luo, H. Pan and E. C. Kinzel, Journal of Manufacturing Science and Engineering, 2014, 136, 061024.

9 J. Klein, M. Stern, G. Franchin, M. Kayser, C. Inamura, S. Dave, J. C. Weaver, P. Houk, P. Colombo, M. Yang and N. Oxman, 3D Print. Addit. Manuf., 2015, 2, 92-105.

10 G. Marchelli, R. Prabhakar, D. Storti and M. Ganter, Rapid Prototyp. J., 2011, 17, 187-194.

11 C. Liu, B. Qian, X. F. Liu, L. M. Tong and J. R. Qiu, RSC Adv., 2018, 8, 16344-16348.

12 X. Chen, W. Liu, B. Dong, J. Lee, H. O. T. Ware, H. F. Zhang and C. Sun, Adv. Mater., 2018, 30, 1705683.

13 N. Bhattacharjee, A. Urrios, S. Kanga and A. Folch, Lab Chip, 2016, 16, 1720-1742.

14 C. R. Li, B. Dong, S. F. Li and C. H. Song, Chem. Phys. Lett., 2007, 443, 426-429.

15 A. M. Malyarevich, I. A. Denisov, K. V. Yumashev, O. S. Dymshits, A. A. Zhilin and U. Kang, Appl. Opt., 2001, 40, 4322-4325.

16 X. J. Zhang, J. Wang, L. Huang, F. J. Pan, Y. Chen, B. F. Lei, M. Y. Peng and M. M. Wu, ACS Appl. Mater. Interfaces, 2015, 7, 10044-10054.

17 W. Chewpraditkul, D. Chen, B. Yu, Q. Zhang, Y. Shen, M. Nikl, R. Kucerkova, A. Beitlerova, C. Wanarak and A. Phunpueok, Phys. Status Solidi RRL, 2011, 5, 40-42.

18 H. Ikeda, T. Murata and S. Fujino, Mater. Chem. Phys., 2015, 162, 431-435.

19 H. Ikeda, S. Fujino and T. Kajiwara, J. Ceram. Soc. Jpn., 2012, 120, 238-242.

20 H. Ikeda, T. Murata and S. Fujino, J. Compos. Mater., 2016, 50, 2541-2547.

21 S. Z. Xu, H. Q. Dou, K. Sun, Y. Y. Ye, Z. X. Li, H. J. Wang, W. Liao, H. Liu, X. X. Miao, X. D. Yuan, X. D. Jiang and X. T. Zu, J. Non-Cryst. Solids, 2018, 492, 56-62.

22 J. W. Chan, T. R. Huser, S. H. Risbud and D. M. Krol, Appl. Phys. A: Mater. Sci. Process., 2003, 76, 367-372.

23 J. W. Chan, T. Huser, S. Risbud and D. M. Krol, Opt. Lett., 2001, 26, 1726-1728.

24 S. T. Selvan, T. Hayakawa and M. Nogami, J. Phys. Chem. B, 1999, 103, 7064-7067.

25 H. J. Bi, W. P. Cai and L. D. Zhang, Mater. Res. Bull., 2000, 35, 1495-1501.

26 Z. Z. Lu, A. J. Fu, S. Y. Xia, A. X. Guan, Y. B. Meng and L. Y. Zhou, J. Electron. Mater., 2018, 47, 4929-4935. 